\title{
Erwiderung hierzu.
}

\section{Von Kurt Huldsehinsky in Berlin.}

Ich stelle fest: mein von B a c h angegriffener Aufsatz „Die OsramVitaluxlampe" ist auf ausdrückliches Ersuchen der Schriftleitung dieser Wochenschrift entstanden. Der Versuch B a c h s, mich als „Propagator" der Vitaluxlampe zu bezeichnen, zu behaupten, ich ,exponiere mich für die Vitaluxlampe“, „,ich setze mich noch sehr für die Vitaluxlampe ein", ich ,propagiere sie neuerdings in einer englischen medizinischen Zeitschrift als ,Ultraviolettstrahler “ “ (die notabene meinen Aufsatz aus der Strahlentherapie ohne mein Wissen übernommen hat), fällt damit in sich zusammen. Ich habe die Vitaluxlampe nur auf ihre biologische Wirksamkeit untersucht und ihre antirachitische Kraft im Tierexperiment dargelegt. Einen anderen Weg zur Feststellung einer Ultraviolettheilkraft gibt es nicht, eine andere, ,s p e z if i s c h e Ultraviolettwirkung" als die von mir 1919 entdeckte a n ti rachi$\mathrm{t}$ i s c h e gibt es nicht. Meine Arbeit konnte erst die Grundlage abgeben zu klinischen Untersuchungen, die eben $\mathrm{B} \mathrm{a} \mathrm{ch}$ schon in statu nascendi zu unterdrücken bestrebt ist, indem er durch phrasenreiche, aber sachlich inhaltlose Fragen und Einwürfe diese ihm als Konkurrenzlampe der Bachschen Höhensonne - Original Hanau - erscheinende Strahlenquelle diskreditieren möchte. Wie wenig ich mich für die Vitaluxlampe "eingesetzt" habe, geht daraus hervor, daß ich ihre Ultraviolettkraft mit der der „Höhensonnenmilch“" verglich, da beiden Agentien zwar eine prophylaktische antirachitische Wirkung, aber keine absolut ausreichende therapeutische zugesprochen werden kann.

"Scheinbestrahlungen" sind kurze Höhensonnenbestrahlungen mit der Quarzlampe - Original Hanau - zur Erzielung einer ,gesunden, braunen Urlaubshaut", Scheinbestrahlungen sind Erythembildungen, die äußerlich ein frisches Aussehen und damit eine UItraviolettheilwirkung vortäuschen sollen. Eine „schwere Gefahr für die Ultravioletttherapie wird heraufbeschworen" nicht durch objektive Untersuchungen neuer Ultraviolettquellen, sondern durch $\mathrm{kr}$ i ti kl o s e Empfehlungen der künstlichen Höhensonne nach $\mathrm{B}$ a $\mathrm{c} \mathrm{h}$ - Original Hanau - bei weit mehr denn 100 Indikationen, durch verantwortungslose Laienpropaganda, durch phantastische Anpreisungen der angeblichen Wirkungen dieser Quarzlampe auch bei dem diesen Fragen fernerstehenden Teil der Aerzteschaft. 